\title{
Alzheimer's Disease and Metabolic Dysfunction: No Association Between L72m Ghlr Variant in Brazilian Population
}

\author{
Daiane Priscila Simão-Silva ${ }^{*}$, Patricia Fernanda Rocha Dias ${ }^{2}$, Micheli Pecharki ${ }^{2}$, Paulo \\ Henrique Ferreira Bertolucci ${ }^{3}$, Lucas Trevisani Rasmussen ${ }^{4}$, Spencer Luiz Marques Payão ${ }^{4}$, \\ Mauro Roberto Piovezan ${ }^{5}$, Helio Afonso Ghizoni Teive ${ }^{5}$, Lupe Furtado-Alle ${ }^{2}$, Ricardo Lehtonen \\ and Rodrigues Souza ${ }^{2}$ \\ ${ }^{1}$ Life Science School, Pontifical Catholic University of Paraná, Brazil \\ ${ }^{2}$ Department of Genetics, Federal University of Paraná, Brazil \\ ${ }^{3}$ Department of Behavioral Neurology, Federal University of São Paulo, Brazil \\ ${ }^{4}$ Department of Genetic and Molecular Biology of Hemocentro, School of Medicine of Marília, Brazil \\ ${ }^{5}$ Department of Neurology and Cognitive Dysfunction Ambulatory, Hospital of Clinics of Federal University of Paraná, Brazil
}

*Corresponding author: Daiane Priscila Simão-Silva, Life Science School, Pontifical Catholic University of Paraná, Curitiba, Brazil.

To Cite This Article: Daiane Priscila Simão-Silva. Alzheimer's Disease and Metabolic Dysfunction: No Association Between L72m Ghlr Variant in Brazilian Population. Am J Biomed Sci \& Res. 2019 - 3(6). AJBSR.MS.ID.000727. DOI: 10.34297/AJBSR.2019.03.000727

Received: June 21, 2019 | Published: July 10, 2019

\section{Abstract}

Introduction: In Alzheimer's disease (AD) the pattern of expression of ghrelin is modified. A reduction in this peptide hormone was observed in some regions of the brain as the hippocampus and the temporal lobe, both associated with cognitive system and memory. Ghrelin is the multifunctional hormone with an important role in regulation of energy balance and metabolic function and is coded by the GHRL gene.

Objective: The aim of this work was to verify the relationship of the L72M GHLR variant, that is associated whit metabolic disorders, with Alzheimer's disease.

Materials and Methods: By case-control association study, DNA samples from 194 AD patients and 201 elderly control (EC) were genotyped for L72M GHLR variant (rs696217).

Results and Discussion: The allele frequencies were similar in cases and controls (72M: 9.07\% and 7.71\%, respectively). These results suggest that L72M variant is not a risk factor to AD. We did not find association with this variant of GHLR, which has a larger correlation with metabolic effects and recent evidence suggests a strict link between metabolic disorders and AD. This work does not exclude the possibility of action of the other variants or epigenetic control factors of GHRL in AD.

Keywords: Ghrelin; L72M Variant; Rs 696217; Neurodegenerative Disease; Metabolic Disorders

\section{Introduction}

In Alzheimer Disease (AD) the pattern of expression of the orexigenic hormone ghrelin is modified [1]. The neurocognitive function have influence for certain peptide hormones by the communication between the gastrointestinal tract and the central nervous system (CNS) [2]. DA is a neurological disorder a profound and progressively cognitive decline is observed, including memory loss, by the functional and morphological deterioration of the hippocampus and temporal lobe with accumulation of aggregates of the amyloid- $\beta$ peptide (A $\beta$ ) and neurofibrillary tangles (NFT) [3]. In these areas of cognitive system and memory a reduction of ghrelin was observed in AD brain [4,5]. Ghrelin is a hormone with a plethora of functions. It is codified by the GHRL gene and contains four exons but only exons 1 and 2 code for the mature peptide [6]. A family of related peptides that can be generated by alternative splicing and/or post-translational modifications from GHRL gene [7]. The L72M (C/A, rs696217, p.L72M, $408 \mathrm{nt}$ ) variant is located 
in exon 2, outside the coding region for mature ghrelin [8]. This variant was associated with increased prevalence of metabolic syndrome [9] which has been considered as a risk factor to AD [10].

Ghrelin is known to play an important role in regulatory system for growth, energy homeostasis and metabolic function [11], is a hormone that stimulates hunger and, interestingly, increased during sleep. Ghrelin has a significant role in neurotrophy, particularly in the hippocampus [4] and in some inflammatory process [12]. It also acts in cognition [5], memory and learning processes. This hormone was correlated with a number of eating and drink disorder [13], and neurological disorders [14,15] such as AD $[4,5,16]$ and influence both synaptic and structural plasticity of determined regions of the brain [2]. Considering that the $\mathrm{AD}$ is deeply affected by the metabolic and inflammatory conditions and ghrelin carry out the regulation of energy balance $[5,17]$ and inflammatory processes we selected a variant of GHRL that was associated with metabolic syndrome and obesity [18], the L72M, to verify the relationship of this variant with AD by a case-control association study. Seminara et al., in review working, argues about the potential therapeutic benefits of ghrelin as a neurocognitive agent and a promising approach to DA [19]. In this context is important to consider the frequencies of variants with potential pharmacogenic as is the variant L72M for DA.

\section{Materials and Methods}

\section{Population samples}

The Brazilian subjects samples, were obtained from Paraná and São Paulo States, from 395 elderly, being 194 AD patients (mean age $76.1 \pm 8.77$; males: 73 , females: 121 ), with age and sex matched with 201 healthy controls (mean age 71.9 \pm 8.25 ; males: 58 , females: 143 ) as of Behavioral Neurology Department UNIFESP/EPM, Geriatric Ambulatory of FAMEMA and Cognitive Dysfunction Ambulatory, Hospital of Clinics UFPR by Paraná State. The AD patients were diagnosed according to the NINCDS-ADRDA (National Institute of Neurological and Communicative Disorders and Stroke-Alzheimer's disease and Related Disorders Association) criteria for probable AD $[20,21]$. The diagnoses were made in the specialized hospitals in diagnosing $\mathrm{AD}$ by the dementia experts. We considered patients with at least one year of evolution of $\mathrm{AD}$, and were contemplated homogeneously all the stages, mild, moderate and severe of the disease. The control group has been previously described [22].

All subjects gave informed consent for participation in this study and this research is approved by the institutional Ethics Committee study (Protocol number 1192.117.11.08). All experiments were conducted in accordance with the Declaration of Helsinki.

\section{Laboratory Analysis}

Venous blood was obtained from all of the participants in a periodic clinical consultation and stored at $-40^{\circ} \mathrm{C}$ after separation of plasma. The total genomic DNA was extracted from peripheral blood samples using a Qiagen extraction kit, according to the manufacturer's instructions, or by a standardized salting out method [23] and then diluted to a final concentration of $20 \mathrm{ng} /$ $\mu \mathrm{L}$. Genotyping of the missense L72M (rs696217; C_3151003_20) variant was performed with the TaqMan genotyping kit assays (Applied Biosystems) by Real Time PCR in a Mastercycler realplex 2. The reactions were performed in the following steps: (1) $50^{\circ} \mathrm{C} / 2$ min, (2) $95{ }^{\circ} \mathrm{C} / 10 \mathrm{~min},(3)$ repeat 50 times $95^{\circ} \mathrm{C} / 15 \mathrm{~s}$, interspersed by $60^{\circ} \mathrm{C} / \mathrm{min}$.

\section{Statistical Analysis}

Allele frequencies were obtained by direct counting the alleles from the observed genotypes. The Hardy-Weiberg equilibrium (HWE) was calculated manually. The chi-square test, used to compare categorical variables, was calculated using Clump software and SPSS version 17.0 for Windows; (Chicago, III., USA). A value of $p$ $<0.05$ was considered statistically significant.

\section{Results}

The genotype distributions of the L72M variant of the GHRL gene were in Hardy-Weinberg (HW) equilibrium in patients (X2 $=1.52$ ) and controls $(X 2=0.03)$. Genotypes and allele frequencies of the GHRL variant analyzed are summarized in Table 1. The genotypic and allele distribution of rs696217 did not show significant differences between cases and controls.

\begin{tabular}{|c|c|c|c|c|c|c|}
\hline \multicolumn{3}{|c|}{ AD } & \multicolumn{2}{|r|}{ EC } & \multirow[t]{2}{*}{$\chi^{2}$} & \multirow[t]{2}{*}{$\mathbf{p}$} \\
\hline & $\mathbf{N}$ & Frequency (\%) & $\mathbf{N}$ & Frequency (\%) & & \\
\hline \multicolumn{7}{|c|}{ GHRL gene (rs696217) } \\
\hline \multicolumn{7}{|c|}{ Genotype } \\
\hline GG & 161 & 83.42 & 171 & 85.07 & \multirow{3}{*}{1.14} & \multirow{3}{*}{0.56} \\
\hline GT & 29 & 15.03 & 29 & 14.43 & & \\
\hline TT & 3 & 1.55 & 1 & 0.5 & & \\
\hline \multicolumn{7}{|c|}{ Alleles } \\
\hline G & 351 & 90.93 & 371 & 92.29 & \multirow{2}{*}{0.47} & \multirow{2}{*}{0.49} \\
\hline $\mathrm{T}$ & 35 & 9.07 & 31 & 7.71 & & \\
\hline
\end{tabular}

\section{Discussion}

Although many researchers have shown that ghrelin is involved in the neuropathology of $\mathrm{AD}[4,5]$, the only study of genetic association between GHRL gene and AD was performed in a Japanese population [16], and this is the first study in a Euroderived population. Similar to our study, Shibata and collaborators 
[16] did not find association between L72M and AD, but their described genotype frequencies were significantly different from our cases and controls ( $p<0.0001)$. In Shibata's study [16] the heterozygote genotype was more frequent than expected and the genotype frequencies were not in HWE. Even so, our data are consistent regarding absence of association in a different population. The L72M variant frequencies from our sample did not differ from another Brazilian population study [24] and other Euro-derived population [25], we did not find statistical difference between the frequencies ( $p>0.7$ and $p>0.2$ respectively).

The L72M variant has been associated with obesity [8] higher triglyceride levels, dietary fat intake and lower HDL-cholesterol [9], higher body mass index (BMI) [26], fat mass and visceral fat [27], modulation of glucose-induced insulin secretion [28], risk for type 2 diabetes [29] and increase in prevalence of metabolic syndrome [9]. This variant, L72M, associated with these various disorders correlated with a physiological condition of insulin-resistance, may modulate glucose-induced insulin secretion [30]. In a study with Wistar rats, Antunes et al., suggest that the fasting ghrelin have a role in the pathogenesis of insulin-resistance by the possible loss of insulin inhibitory effect may be an adaptive metabolic adjustment. More studies are needed to understand these pathways [31]. Currently many positive associations have been reported between Alzheimer's disease and metabolic factors such as obesity, abdominal adiposity, [29] diabetes and insulin resistance, BMI [29], abnormal glucose and insulin levels [32], and metabolic syndrome [10]. Metabolic disturbance is an important factor contributing to neurodegenerative diseases; however, the neuropathological mechanisms underlying these changes are not yet clear [33]. The GHRL gene is very complex and can be regulated at multiple levels [7]. The L72M variant, located outside the coding region for mature ghrelin, could alter the stability of the mRNA or interfere with the splicing of the prepro-hormone. Despite the recent evidence that suggests a strict link between metabolic disorders and AD [10,34], in this work we did not find association with the variant of Ghrelin that has a known correlation with metabolic effects. Gahete et al. [1] argues for a need to establish the precise role of the ghrelin system in AD. Although the L72M mutation does not affect the susceptibility to $\mathrm{AD}$, it does not exclude the possibility of action of other variants or epigenetic control factors of GHRL gene in Alzheimer's disease.

\section{Acknowledgments}

Grants and scholarships were received from Coordination for Improvement of Higher Education (CAPES).

\section{Disclosure Statement}

We have no potential conflicts of interest.

\section{References}

1. Gahete MD, Cordoba-Chacon J, Kineman RD, Luque RM, Castano JP (2011) Role of ghrelin system in neuroprotection and cognitive functions: implications in Alzheimer's disease. Peptides 32(11): 22252228.

2. Mainardi M. Fusco S. Grassi C (2015) Modulation of Hippocampal Neural Plasticity by Glucose-Related Signaling. Neural Plasticity 657928.

3. Mattson MP (2004) Pathways towards and away from Alzheimer's disease. Nature 430(7000):631-639.
4. Diano S, Farr SA, Benoit SC, Mc Nay EC, da Silva I, et al. (2006) Ghrelin controls hippocampal spine synapse density and memory performance. Nat Neurosci 9(3): 381-388.

5. Gahete MD, Rubio A, Cordoba-Chacon J, Gracia-navarro F, Kineman RD, et al. (2010) Expression of the ghrelin and neurotensin systems is altered in the temporal lobe of Alzheimer's disease patients. J Alzheimers Dis 22(3): 819-828.

6. Korbonits M, Grossman AB (2004) Ghrelin: update on a novel hormonal system. Eur J Endocrinol 151(Suppl 1): S67-70.

7. Seim I, Herington AC, Chopin LK (2009) New insights into the molecular complexity of the ghrelin gene locus. Cytokine Growth Factor Rev 20(4): 297-304.

8. Miraglia del Giudice E, Santoro N, Cirillo G, et al. (2004) Molecular screening of the ghrelin gene in Italian obese children: the Leu72Met variant is associated with an earlier onset of obesity. Int J Obes Relat Metab Disord 28(3): 447-450.

9. Steinle NI, Pollin TI, O’Connell JR, Mitchell BD, Shuldiner A (2005) Variants in the ghrelin gene are associated with metabolic syndrome in the Old Order Amish. J Clin Endocrinol Metab 90(12): 6672-6677.

10. Frisardi V, Imbimbo BP (2012) Metabolic-cognitive syndrome: metabolic approach for the management of Alzheimer's disease risk. J Alzheimers Dis 30(Suppl 2): S1-4.

11. van der Lely AJ, Tschop M, Heiman ML, Ghigo E (2004) Biological, physiological, pathophysiological, and pharmacological aspects of ghrelin. Endocr Rev 25(3): 426-457.

12. Dixit VD, Schaffer EM, Pyle RS, Collins GD, Sakthivel SK, et al. (2004) Ghrelin inhibits leptin- and activation-induced proinflammatory cytokine expression by human monocytes and T cells. J Clin Invest 114(1): 57-66.

13. Monteleone P, Tortorella A, Castaldo E, Di Filippo C, Maj M (2007) The Leu72Met polymorphism of the ghrelin gene is significantly associated with binge eating disorder. Psychiatr Genet 17(1):13-16.

14. Cummings DE, Clement K, Purnell JQ Vaisse C, foster KE, et al. (2002) Elevated plasma ghrelin levels in Prader Willi syndrome. Nat Med; 8(7): 643-644.

15. Andrews ZB, Erion D, Beiler R, Liu ZW, Abizaid A, et al. (2009) Ghrelin promotes and protects nigrostriatal dopamine function via a UCP2dependent mitochondrial mechanism. J Neurosci 29(45): 14057-14065.

16. Shibata N, Ohnuma T, Kuerban B, Komatsu M, Arai H (2011) Genetic association between ghrelin polymorphisms and Alzheimer's disease in a Japanese population. Dement Geriatr Cogn Disord 32(3): 178-181.

17. De Vriese C, Delporte C (2007) Influence of ghrelin on food intake and energy homeostasis. Curr Opin Clin Nutr Metab Care 10(5): 615-619.

18. Pulkkinen L, Ukkola O, Kolehmainen M, Uusitupa M (2010) Ghrelin in diabetes and metabolic syndrome. Int J Pept P. 248948.

19. Seminara R S. Jeet C, Biswas S. Kanwal B, Iftikhar W, et al. (2018) The Neurocognitive Effects of Ghrelin- induced Signaling on the Hippocampus: A Promising Approach to Alzheimer's Disease. Cureus 10(9): e3285.

20. McKhann G, Drachman D, Folstein M, Katzman R, Price D, et al. (1984) Clinical diagnosis of Alzheimer's disease: report of the NINCDS-ADRDA Work Group under the auspices of Department of Health and Human Services Task Force on Alzheimer's Disease. Neurology 34(7): 939-944.

21. Howard MW, Youker TE, Venkatadass VS (2008) The persistence of memory: contiguity effects across hundreds of seconds. Psychon Bull Rev 15(1): 58-63.

22. Simao-Silva DP, Bertolucci PH, de Labio RW, Payao SL, Furtado-Alle $\mathrm{L}$, et al. (2013) Association analysis between $\mathrm{K}$ and $-116 \mathrm{~A}$ variants of butyrylcholinesterase and Alzheimer's disease in a Brazilian population. Chem Biol Interact 203(1): 358-360. 
23. Lahiri DK, Nurnberger JI (1991) A rapid non-enzymatic method for the preparation of HMW DNA from blood for RFLP studies. Nucleic Acids Res 19(19): 5444.

24. Dantas VG, Furtado-Alle L, Souza RL (2011) Chautard-FreireMaia EA. Obesity and variants of the GHRL (ghrelin) and BCHE (butyrylcholinesterase) genes. Genet Mol Biol 34(2): 205-207.

25. Sherry ST, Ward MH, Kholodov M, baker J, Phan L, et al. (2001) dbSNP: the NCBI database of genetic variation. Nucleic Acids Res 29(1):308-311.

26. Ukkola O, Ravussin E, Jacobson P, Perusse L, rankinen T, et al. (2002) Role of ghrelin polymorphisms in obesity based on three different studies. Obes Res 10(8): 782-791.

27. Korbonits M, Gueorguiev M, O’Grady E, lecoeur C, Swan DC, et al. (2002) A variation in the ghrelin gene increases weight and decreases insulin secretion in tall, obese children. J Clin Endocrinol Metab 87(8): 40054008.

28. Liao N, Xie ZK, Huang J, Xie ZF (2013) Association between the ghrelin Leu72Met polymorphism and type 2 diabetes risk: A meta-analysis. Gene 517(2): 179-183.
29. Profenno LA, Porsteinsson AP, Faraone SV (2010) Meta-analysis of Alzheimer's disease risk with obesity, diabetes, and related disorders. Biol Psychiatry 67(6): 505-512.

30. Korbonits M. Gueorguiev M. O'Grady E, lecoeur C, Swan DC, et al. (2002) A variation in the ghrelin gene increases weight and decreases insulin secretion in tall, obese children. J. Clin. Endocr. Metab 87: 4005-4008.

31. Antunes LC. Jornada MN. Elkfury JL, Foletto KC, Bertoluci MC, (2014) Fasting ghrelin but not PYY(3-36) is associated with insulin-resistance independently of body weight in Wistar rats. Arq Bras Endocrinol Metab 58: 377-381.

32. Luchsinger JA, Tang MX, Shea S, Mayeux R. (2004) Hyperinsulinemia and risk of Alzheimer disease. Neurology 63(7): 1187-1192.

33. Craft S (2005) Insulin resistance and cognitive impairment: a view through the prism of epidemiology. Arch Neurol 62(7): 1043-1044.

34. Craft S (2009) The role of metabolic disorders in Alzheimer disease and vascular dementia: two roads converged. Arch Neurol 66(3): 300-305. 